\title{
Smart utilization of cobalt-based double perovskite cathodes on barrier-layer-free zirconia electrolyte of solid oxide fuel cells
}

Meng Li ${ }^{\mathrm{a}, \mathrm{b}}$, Kongfa Chen ${ }^{\mathrm{b}}$, Bin $\mathrm{Hua}^{\mathrm{c}}$, Jing-li Luo ${ }^{\mathrm{c}}$, William D.A. Rickard ${ }^{\mathrm{d}}$, Jian Li ${ }^{\mathrm{a}}{ }^{*}$, John T.S. Irvine $\mathrm{e}^{\mathrm{e}}$ and San Ping Jiang ${ }^{\mathrm{b}, *}$

${ }^{*}$ Corresponding authors

${ }^{a}$ Center for Fuel Cell Innovation, State Key Laboratory for Coal Combustion, School of Materials Science and Engineering, Huazhong University of Science and Technology, Wuhan, Hubei 430074, China. Tel.: +86 27 87557694; fax: +86 27 87558142. E-mail address: lijian@hust.edu.cn.

${ }^{\mathrm{b}}$ Fuels and Energy Technology Institute \& Department of Chemical Engineering, Curtin University, Perth, WA 6102, Australia. E-mail address: s.jiang@curtin.edu.au.

'Department of Chemical and Materials Engineering, University of Alberta, Edmonton, Alberta T6G 2G6, Canada.

dJohn De Laeter Centre \& Department of Physics and Astronomy, Curtin University, Perth, WA 6102, Australia.

eSchool of Chemistry, University of St Andrews, Fife KY16 9ST, UK. 


\section{Abstract}

Cobaltite-based double perovskite oxides with high electrocatalytic activity and conductivity have been developed as high-performance cathode alternatives for solid oxide fuel cells (SOFCs). However, the use of cobaltite-based double perovskites on $\mathrm{Y}_{2} \mathrm{O}_{3}$ stabilized $\mathrm{ZrO}_{2}$ (YSZ)-based SOFCs requires the application of a doped ceria barrier layer. This is due to their poor chemical and physical compatibility with YSZ electrolyte during high-temperature sintering and fabrication process. Here we report a viable approach of in operando assemble double perovskites such as $\operatorname{PrBa}_{0.5} \mathrm{Sr}_{0.5} \mathrm{Co}_{1.5} \mathrm{Fe}_{0.5} \mathrm{O}_{5+\delta}$ (PBSCF) on YSZ electrolyte and thus effectively form an electrode/electrolyte interface without high temperature processing. The electrochemical performance of the in situ assembled PBSCF cathode is comparable to that of the cathode prepared by the conventional method. A single cell with an in situ assembled PBSCF-GDC (Gd-doped ceria) cathode achieved a peak power density (PPD) of $1.37 \mathrm{~W} \mathrm{~cm}^{-2}$ at $750{ }^{\circ} \mathrm{C}$ and exhibited a high stability at $500 \mathrm{~mA} \mathrm{~cm}^{-2}$ and $750{ }^{\circ} \mathrm{C}$ for $100 \mathrm{~h}$. Surface and cross-sectional microstructure analysis offer solid evidence that the PBSCF-GDC cathode/YSZ electrolyte interface was formed by electrochemical polarization. This work offers new opportunities to effectively and effortlessly use high-performance double perovskite cathodes in commercial SOFCs. 


\section{Introduction}

Solid oxide fuel cells (SOFCs) are great prospects for efficient and environmentally friendly energy conversion. Although their high operating temperature contributes to a high reaction rate, it also accelerates the degradations of both the cell and stack components. In this context, increasing efforts have been devoted to reducing the operating temperature to intermediate temperatures (500 800 ${ }^{\circ} \mathrm{C}$ ). It has been found that the high cathodic overpotential loss becomes the key factor which undermines the performances of the SOFCs operating at reduced temperatures. $^{1-3}$ Thus, in order to improve the kinetics of the oxygen reduction reaction of SOFCs, considerable efforts have been made in the development of new cathodic materials with high activity and stability.

Recently, single-phase cobaltite-based perovskite materials, such as $\mathrm{LnBaCo}_{2} \mathrm{O}_{5+\delta}(\mathrm{Ln}=\mathrm{Y}, \mathrm{Gd}, \mathrm{Sm}, \mathrm{Nd}, \mathrm{Pr})$ have been the subject of growing research activity for the ORR. Typically, they show a cation-ordered structure with alternating Ln-O and Ba-O layers. ${ }^{4-6}$ Through proper ion substitution on both A and B sites, their physicochemical properties, such as electrical conductivities, electrochemical performances and redox stability could be effectively improved. For instance, $\mathrm{PrBa}_{0.5} \mathrm{Sr}_{0.5} \mathrm{Co}_{1.5} \mathrm{Fe}_{0.5} \mathrm{O}_{5+\delta}$ (PBSCF) ${ }^{7-9}$ showed the best electrochemical performance with very low area specific resistance (ASR) for oxygen reduction reaction (ORR), $\sim 0.33 \Omega \mathrm{cm}^{2}$ at $500{ }^{\circ} \mathrm{C}$ and $\sim 0.056 \Omega \mathrm{cm}^{2}$ at $600{ }^{\circ} \mathrm{C}$. A Ni-GDC $\mid$ GDC $\mid$ PBSCF-GDC test cell demonstrated peak power density of $\sim 2.16 \mathrm{~W} \mathrm{~cm}^{-2}$ at $600{ }^{\circ} \mathrm{C}$ and stable power output at $550{ }^{\circ} \mathrm{C}$ for $150 \mathrm{~h}$ under a cell voltage of $0.6 \mathrm{~V}$. Unfortunately, the 
practical application of these promising double perovskite materials is restrained due to their poor physicochemical compatibility with the state-of-art yttria-stabilized zirconia (YSZ) electrolyte. Double perovskites readily react with YSZ electrolyte during the high temperature sintering and fabrication process. In addition, the thermal expansion coefficients are vastly different from that of YSZ. Generated thermal stress at high temperatures may lead to detachment of cathode layer. A GDC buffer layer is generally adopted to prevent interactions between cathode and YSZ electrolyte layers, notwithstanding the TEC mismatch issue remains. The doped ceria buffer layer needs to be dense and pinhole-free and requires the careful control of the microstructure of the barrier layer and additional fabrication and sintering steps. In the case of metal-supported SOFCs cathodes cannot be sintered in an oxidizing atmosphere at above $1000{ }^{\circ} \mathrm{C}$ due to the deformation of the metal-support as a result of oxidation at high temperatures. ${ }^{10-13}$ Thus, in order to use cobaltite-based cathodes such as

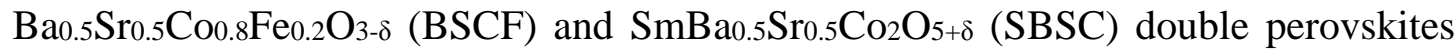
on a ferritic stainless steel (STS430) supported full cell, GDC buffer layer was used without pre-sintering to prevent possible chemical reactions between YSZ electrolyte and cathode materials cathode layer. ${ }^{10,11}$ However, surface segregated $\mathrm{Sr}$ could migrate through the porous ceria barrier layer, forming insulating phase at the interface.

Most recently, we studied thermally and electrochemically induced electrode/electrolyte interfaces on pre-sintered and in situ assembled LSM and LSCF electrodes on YSZ and GDC electrolytes and found that electrode/electrolyte 
interfaces can be formed on the in situ assembled cathodes under cathodic polarization conditions without the high temperature sintering process. ${ }^{14}$ Although the topography of the electrochemically induced interface is very different from that of one formed under the conventional high temperature sintering, their electrocatalytic activities for the oxygen reduction reaction are close and comparable. In this study, the PBSCF and PBSCF-GDC cathodes were directly applied on anode-supported YSZ electrolyte based cells via in situ assembly method. The electrochemically induced cathode/YSZ electrolyte interfaces were formed by polarization at $500 \mathrm{~mA} \mathrm{~cm}^{-2}$ and $750{ }^{\circ} \mathrm{C}$ for $2 \mathrm{~h}$ and showed high activity and stability under SOFC operation conditions.

\section{Experimental}

\subsection{Materials}

$\mathrm{PrBa}_{0.5} \mathrm{Sr}_{0.5} \mathrm{Co}_{1.5} \mathrm{Fe}_{0.5} \mathrm{O}_{5+\delta}$ (PBSCF) double perovskite was used as cathode material. To prepare PBSCF powder, $\mathrm{Pr}\left(\mathrm{NO}_{3}\right)_{3} \cdot 6 \mathrm{H}_{2} \mathrm{O}$ (Aldrich Chemistry), $\mathrm{Ba}\left(\mathrm{NO}_{3}\right)_{2}$ (Scharlau), $\quad \mathrm{Sr}\left(\mathrm{NO}_{3}\right)_{2} \quad$ (Chem-Supply), $\quad \mathrm{Co}\left(\mathrm{NO}_{3}\right)_{2} \cdot 6 \mathrm{H}_{2} \mathrm{O} \quad$ (Sigma-Aldrich) and $\mathrm{Fe}\left(\mathrm{NO}_{3}\right)_{3} \cdot 9 \mathrm{H}_{2} \mathrm{O}$ (Sigma-Aldrich) were initially dissolved in distilled water. Ethylene glycol and citric acid were added into the solution sequentially as the chelant agents. The molar ration of total metal ions, ethylene glycol and citric acid was $1: 1.5: 3$. The solution was stirred and heated at $80{ }^{\circ} \mathrm{C}$ for $2 \mathrm{~h}$, and then vaporized in an oven at $150{ }^{\circ} \mathrm{C}$, followed by calcination in air at $1050{ }^{\circ} \mathrm{C}$ for $10 \mathrm{~h}$ to form layered perovskite PBSCF.

\subsection{Cell fabrication}


The anode-supported full cells $(\phi 13 \mathrm{~mm} \times 1 \mathrm{~mm})$ were prepared by tape-casting, screen printing and co-sintering process. The anode support substrate containing $\mathrm{NiO}$ (Inco) and $8 \mathrm{~mol} . \% \mathrm{Y}_{2} \mathrm{O}_{3}$ stabilized $\mathrm{ZrO}_{2}$ (8YSZ, Tosoh) at a weight ratio of 57:43 was obtained by tape-casting. The NiO-YSZ (60:40) functional anode and YSZ electrolyte slurry were screen printed on one side of the anode support substrate in sequence, before sintered in air at $1390{ }^{\circ} \mathrm{C}$ for $3 \mathrm{~h}$. To fabricate the PBSCF on YSZ electrolyte layer via conventional method, a GDC $\left(\mathrm{Ce}_{0.9} \mathrm{Gd}_{0.1} \mathrm{O}_{1.95}\right.$, AGC Semi Chemical CO., Ltd) buffer layer was fabricated on the YSZ electrolyte layer by spin coating and sintering at $1300{ }^{\circ} \mathrm{C}$ for $10 \mathrm{~h}$. PBSCF cathode layer was then applied to the GDC buffer layer, followed by sintering at $950{ }^{\circ} \mathrm{C}$ in air for $4 \mathrm{~h}$. In the case of in situ assembled PBSCF cathode, the cathode layer was painted directly on the YSZ electrolyte layer and dried at $100{ }^{\circ} \mathrm{C}$ for $1 \mathrm{~h}$ with no additional pre-sintering step at high temperatures. In situ assembled PBSCF-GDC (60:40) cathodes were prepared in similar way. The cathode area was $0.32 \mathrm{~cm}^{2}$. Pt paste (Sino-Platinum Metals Co., Ltd) used as current collector was painted on the anode and cathode of as-prepared cells and dried at $100{ }^{\circ} \mathrm{C}$ for $1 \mathrm{~h}$.

\subsection{Characterization}

The phase formation of as-prepared cathode powders was identified by X-ray diffraction (XRD). A thermal dilatometer (Linseis, L75 Platinum series) was used to examine the thermal expansion coefficient (TEC) of dense PBSCF sample in air from 200 to $900{ }^{\circ} \mathrm{C}$.

Electrochemical polarization and impedance measurements were conducted by a 
four probe method using a Zahner electrochemical workstation. Pt mesh and wires (Sino-Platinum Metals Co., Ltd) were used as current collector and measuring probes. The cells were sealed onto a cell holder $\left(\mathrm{Al}_{2} \mathrm{O}_{3}\right.$ tube) by using a Ceramabond ${ }^{\circledR}$ glass sealant (Aremco Product, Inc.) and the NiO-YSZ anode was reduced by passing pure $\mathrm{H}_{2}$ while being heated up. The cathodes were sintered in situ during heating up the cell to $750{ }^{\circ} \mathrm{C}$, and then polarized at current density of $500 \mathrm{~mA} \mathrm{~cm}{ }^{-2}$ for $2 \mathrm{~h}$. After initial polarization, the electrochemical impedance spectra (EIS) and current density-voltage-power density (I-V-P) curves were measured at temperatures ranging from 650 to $750{ }^{\circ} \mathrm{C}$. The stability of full cells with in situ assembled PBSCF-GDC cathode was evaluated at $750{ }^{\circ} \mathrm{C}$ by applying constant current and simultaneously keeping tracking of the voltage. Both $\mathrm{H}_{2}$ and air were fed at a constant rate of $100 \mathrm{~mL}$ $\min ^{-1}$ as fuel and oxidant, respectively, for all tests.

The microstructure of the cell with the composite cathode was examined by scanning electron microscope (SEM, Neon 40EsB) after polarization treatment. The topography at the cathode/electrolyte interface before and after polarization treatments was investigated using atomic force microscopy (AFM, Bruker's Dimension FastScan) with tapping mode and time-of-flight secondary ion mass spectrometry (TOF-SIMS, Lyra FIB-SEM). To investigate the cathode/electrolyte interface, the cathode layer was removed by immersing in $\mathrm{HCl}$ solution and ultrasonic bath for $15 \mathrm{~min}$. Then the samples were left in the $\mathrm{HCl}$ for $24 \mathrm{~h}$ before cleaned thoroughly with distilled water.

\section{Results and discussion}




\subsection{Phase and morphology characterization}

Fig. 1 shows XRD and TEC results of synthesized PBSCF. The XRD pattern of as-prepared PBSCF powder is shown in Fig. 1a. The pattern shows only peaks associated with double perovskite structure without any evidence of the existence of any other impurities, according to JCPDS cards 00-053-0131 of $\mathrm{PrBaCo}_{2} \mathrm{O}_{5.68}$. This indicates that the as-synthesized PBSCF powder is pure double perovskite phase. The thermal expansion curve of PBSCF is not exactly linearly dependent on temperature, with an inflection occurring on the slope around $650{ }^{\circ} \mathrm{C}$ (Fig. 1b). The TEC value is $15.2 \times 10^{-6} \mathrm{~K}^{-1}$ from 200 to $650{ }^{\circ} \mathrm{C}$, and it increases to $31.5 \times 10^{-6} \mathrm{~K}^{-1}$ at temperatures ranging from 650 to $900{ }^{\circ} \mathrm{C}$. The reported TEC values are in the range of 10.3 to $10.7 \times 10^{-6} \mathrm{~K}^{-1}$ for YSZ electrolyte. ${ }^{15-17}$ The TEC value of PBSCF is much higher than that of the YSZ electrolyte. Nevertheless, the thermal mismatch between the YSZ electrolyte and double perovskite electrode could be accommodated by the loose and non-rigid microstructure of the in situ assembled electrode due to the absence of the high temperature sintering process.

\subsection{Performance with in situ assembled pristine and composite cathodes}

It is essential to compare performance difference of two full cells with PBSCF cathodes prepared by in situ assembling method and conventional method, respectively. Fig. 2a shows the polarization performance of cell with in situ assembled PBSCF cathode measured at $750{ }^{\circ} \mathrm{C}$ with $\mathrm{H}_{2}$ as fuel and air as oxidant. The initial peak power density (PPD) is $0.48 \mathrm{~W} \mathrm{~cm}^{-2}$. After a polarization current density of 500 $\mathrm{mA} \mathrm{cm}{ }^{-2}$ was applied to the cell for $2 \mathrm{~h}$, the PPD is $0.54 \mathrm{~W} \mathrm{~cm}^{-2}$ at $750{ }^{\circ} \mathrm{C}$, an $12.5 \%$ 
increase as compared to that before polarization treatment. The results indicate that the polarization current passage improves the performance of the cells with in situ assembled PBSCF cathode. The promotion effect of polarization treatment on the cell performance is also confirmed by the impedance responses, as shown in Fig. 3b. The initial overall cell polarization and ohmic resistances $\left(\mathrm{R}_{\mathrm{p}}\right.$ and $\mathrm{R} \Omega$ ) are 0.95 and $0.25 \Omega$ $\mathrm{cm}^{2}$, respectively, and decrease to 0.65 and $0.23 \Omega \mathrm{cm}^{2}$ after polarization. In the case of the cell with pre-sintered PBSCF cathode, the PPD is $0.62 \mathrm{~W} \mathrm{~cm}^{-2}$ under the same conditions (Fig. 3a), slightly higher than that of the cell with in situ assembled PBSCF cathode. The cell with pre-sintered PBSCF cathode has similar ohmic resistance with that of the cell with in situ assembled PBSCF cathode, while its higher performance results from its lower $R_{p}, 0.44 \Omega \mathrm{cm}^{2}$. The close polarization performance of cells with in situ assembled and pre-sintered PBSCF cathodes indicates the feasibility of the in situ assembly method in the development of cobaltite-based double perovskite cathodes on YSZ electrolyte cells. As the $\mathrm{R}_{\mathrm{p}}$ is strongly related to contact between PBSCF particles and the interfaces, optimization of the cathodic current treatment could further reduce $\mathrm{R}_{\mathrm{p}}$.

Figure 3 shows the electrochemical performance of the cell with an in situ assembled PBSCF-GDC composite cathode. The initial peak power density before polarization treatment is $1.11 \mathrm{~W} \mathrm{~cm}^{-2}$ (Fig. 3a), much higher than that of the cell with the in situ assembled pristine PBSCF cathode. After polarization treatment at $500 \mathrm{~mA}$ $\mathrm{cm}^{-2}$ and $750{ }^{\circ} \mathrm{C}$ for $2 \mathrm{~h}$, the peak power density increases to $1.37 \mathrm{~W} \mathrm{~cm}^{-2}$. The increase in power output is $23.4 \%$, also higher than $12.5 \%$ performance improvement 
experienced by the cell with pristine PBSCF cathode. The power density is 0.88 and $0.49 \mathrm{~W} \mathrm{~cm}^{-2}$ at 700 and $650{ }^{\circ} \mathrm{C}$, respectively. The impedance behavior is similar to the polarization performance. Similar to the cell with pristine PBSCF cathode, both $\mathrm{R}_{\Omega}$ and $\mathrm{R}_{\mathrm{p}}$ of the cell with PBSCF-GDC composite cathode decrease after the polarization treatment (Fig. 4b). The $\mathrm{R} \Omega$ decreased from 0.24 to $0.20 \Omega \mathrm{cm}^{2}$ whilst the $\mathrm{R}_{\mathrm{p}}$ decreased from 0.52 to $0.32 \Omega \mathrm{cm}^{2}$ at $750{ }^{\circ} \mathrm{C}$. The decrease in polarization resistance, $\mathrm{R}_{\mathrm{p}}$, is $38.5 \%$, much higher than that of the cell with PBSCF cathode, consistent with the significant improvement of the performance. The significant reduction in both $R_{\Omega}$ and $R_{p}$ shows that cathodic polarization current not only improves the physical contact between the cathode and YSZ electrolyte interface, but also the contact between PBSCF and GDC particles within the composite cathode. The $\mathrm{R}_{\mathrm{p}}$ is 0.58 and $0.89 \Omega \mathrm{cm}^{2}$ at 700 and $650{ }^{\circ} \mathrm{C}$, respectively.

The stability of the SOFCs is an important factor in the evaluation of the electrochemical activity of the electrodes. Fig. 4a shows the stability test of the cells with in situ assembled PBSCF-GDC composite cathode under a constant current density of $500 \mathrm{~mA} \mathrm{~cm}^{-2}$ at $750{ }^{\circ} \mathrm{C}$. The voltage initially increases from 0.87 to $0.92 \mathrm{~V}$, and stays around $0.92 \mathrm{~V}$ for $70 \mathrm{~h}$, showing rather stable performance. However, the cell voltage decreases slightly to $0.88 \mathrm{~V}$ with further polarization. The $\mathrm{R} \Omega$ remains approximately the same value before and after the $100 \mathrm{~h}$ test, as shown in Fig. 4b. The $\mathrm{R}_{\mathrm{p}}$ is $0.30 \Omega \mathrm{cm}^{2}$ after tested for $50 \mathrm{~h}$, very close to the initial value $0.32 \Omega \mathrm{cm}^{2}$ of the cell before the test, and it increases slightly to $0.42 \Omega \mathrm{cm}^{2}$ at the end of the test. The increase in polarization resistance is mainly on the low frequencies. The impedance 
responses of the cells can be characterized by a small depressed high-frequency arc and a large low-frequency arc, as normally observed for conventional anode supported SOFCs. ${ }^{18,19}$ The high-frequency region is normally dominated by cathode process while the low-frequency region can be mainly contributed to anode process. ${ }^{20-22}$ An equivalent circuit with two RQ ( $\mathrm{R}$ is electrode polarization resistance and Q is the constant phase element) elements in series was used for the EIS analysis and the fitting data are shown in Fig. 4b. The polarization resistance values of both high- and low-frequency arc slightly increase after the long-term polarization, as shown in Fig. 4c. As the low frequency of the cell is primarily related to the impedance of the anode of the cell, the small degradation of the cell with in situ assembled PBSCF-GDC cathode is also caused by the deterioration of the Ni-YSZ anode.

\subsection{Microstructure and AFM analysis of the interface}

Fig. 5 shows the SEM micrographs of the cross-sections of the cell with in situ assembled PBSCF-GDC composite cathode after tested at $500 \mathrm{~mA} \mathrm{~cm}{ }^{-2}$ and $750{ }^{\circ} \mathrm{C}$ for $100 \mathrm{~h}$. The thickness of composite cathode is $\sim 20 \mu \mathrm{m}$ and the thickness of the YSZ electrolyte layer is $6.5 \mu \mathrm{m}$. The PBSCF-GDC cathode is well adhered to YSZ electrolyte layer, and the composite cathode is characterized by a mixture of large and small particles (Fig. 5b). The morphology and microstructural change at the cathode/electrolyte interfaces before and after the durability test were investigated by AFM, and the results are shown in Fig. 6. The freshly prepared YSZ surface is clean with clear grains and boundaries (Fig. 6a). After polarization at $500 \mathrm{~mA} \mathrm{~cm}{ }^{-2}$ and 
$750{ }^{\circ} \mathrm{C}$ for $100 \mathrm{~h}$, there are large number of contact marks formed on the YSZ electrolyte surface in contact with the in situ assembled PBSCF-GDC composite cathode (Fig. 6b-c). The size of the contact marks is in the range of $0.1-1 \mu \mathrm{m}$. The contact marks are randomly distributed on the surface of YSZ electrolyte, indicating the formation of such formed contact marks is the result of the polarization under SOFC operation conditions. The height profiles along selected three contact marks are given in Fig. 6e. For an individual particle (green line), the difference in height between the highest and lowest points is $24 \mathrm{~nm}$, much lower than its width of $170 \mathrm{~nm}$, which implies the formation of electrode/electrolyte interface. Some small particles aggregate to form islands. The thickness of the islands marked by red and blue lines is 80 and $180 \mathrm{~nm}$, respectively.

The composition and distribution of elements on the YSZ electrolyte surface of the cells after the stability test were investigated by the TOF-SIMS technique and the results are shown in Figure 7 . A $10 \times 10 \mu \mathrm{m}$ scan area was analyzed with the depth of $160 \mathrm{~nm}$ (indicated in the Fig.7a). There are large number of particles embedded in YSZ grains forming good contact between the YSZ electrolyte layer and the cathode layer, consistent with the AFM result in Fig. 6. The element mapping of Zr, Ce, Ba and $\mathrm{Sr}$ at the depth of $50 \mathrm{~nm}$ are shown in Fig. 7b. Strong signal of $\mathrm{Zr}$ is detected on the whole area, while Ce element is also detected on the YSZ electrolyte surface. However, the signals of $\mathrm{Ba}$ and $\mathrm{Sr}$ are extremely weak as compared to that of Ce, which implies that most of those remained particles on the YSZ surface are GDC particles from the cathode layer. The results indicate that cathodic polarization current 
could be beneficial for the interfacial contact between GDC and YSZ electrolyte.

The in situ assembly of PBSCF electrode on YSZ electrolyte and the formation of electrode/electrolyte interface under the influence of cathodic polarization are schematically shown in Fig.8. In this in situ assembly route, the cathode powder is directly applied on barrier-layer-free YSZ electrolyte, followed by in situ assembling under operation conditions. The current passage works as a driving force for the contact and interface between the PBSCF and GDC particles, forming passages for ionic and electronic transfer (Fig.8c). More importantly, the interfaces between the YSZ electrolyte and the cathode can be formed electrochemically in situ under SOFC operation conditions (Fig. 8d). ??

\section{Conclusions}

In this study, in situ assembling method was used to apply PBSCF double perovskite cathode material directly to Ni-YSZ anode supported YSZ electrolyte based SOFCs. After polarization treatment at $500 \mathrm{~mA} \mathrm{~cm}-2$ and $750{ }^{\circ} \mathrm{C}$ for $2 \mathrm{~h}$, electrochemical performance of the cells was remarkably improved. Cathodic polarization reduced the cell ohmic resistance, indicating the formation of electrochemically induced interface. This is confirmed by the AFM examination of the YSZ electrolyte surface in contact with the in situ assembled PBSCF-GDC cathodes. In the case of the cell with in situ assembled PBSCF-GDC composite cathode, the maximum power density was $1.37 \mathrm{~W} \mathrm{~cm}^{-2}$ at $750{ }^{\circ} \mathrm{C}$. And it shows quite high stability under polarization conditions of $500 \mathrm{mAcm}^{-2}$ and $750{ }^{\circ} \mathrm{C}$ for $100 \mathrm{~h}$. The 
TOF-SIM analysis reveals that large number of GDC particles were embedded in YSZ grains forming good contact between the electrolyte and cathode layers after polarization. The above results demonstrate that the in situ assembly method is an effective approach to directly apply cobaltite-based double perovskite cathodes to YSZ electrolyte based SOFCs.

\section{Acknowledgements}

This project is supported by the National Natural Science Foundation of China (project number: 51472099) and the Australian Research Council under the Discovery Project Scheme (project number: DP150102025 \& DP150102044). The authors acknowledge the facilities, scientific and technical assistance of the Curtin University Microscopy \& Microanalysis Facility, Curtin University. 


\section{References}

1. S. P. Jiang, Journal of Materials Science, 2008, 43, 6799-6833.

2. E. P. Murray, T. Tsai and S. A. Barnett, Solid State Ionics, 1998, 110, 235-243.

3. Y. Takeda, R. Kanno, M. Noda, Y. Tomida and O. Yamamoto, J. Electrochem. Soc., 1987, 134, 2656-2661.

4. R. Pelosato, G. Cordaro, D. Stucchi, C. Cristiani and G. Dotelli, J. Power Sources, 2015, 298, 46-67.

5. A. Y. Suntsov, I. A. Leonidov, M. V. Patrakeev and V. L. Kozhevnikov, Solid State Ionics, 2015, 274, 17-23.

6. M. Burriel, J. Pena-Martinez, R. J. Chater, S. Fearn, A. V. Berenov, S. J. Skinner and J. A. Kilner, Chem Mater, 2012, 24, 613-621.

7. S. Choi, S. Yoo, J. Kim, S. Park, A. Jun, S. Sengodan, J. Kim, J. Shin, H. Y. Jeong, Y. Choi, G. Kim and M. Liu, Scientific Reports, 2013, 3, 2426.

8. L. Jiang, T. Wei, R. Zeng, W.-X. Zhang and Y.-H. Huang, J Power Sources, 2013, 232, 279-285.

9. S. Park, S. Choi, J. Shin and G. Kim, RSC Advances, 2014, 4, 1775-1781.

10. Y.-M. Kim, P. Kim-Lohsoontorn and J. Bae, J Power Sources, 2010, 195, 6420-6427.

11. S.-W. Baek, J. Jeong, Y.-M. Kim, J. H. Kim, S. Shin and J. Bae, Solid State Ionics, 2011, 192, 387-393.

12. C. Lee and J. Bae, J Power Sources, 2008, 176, 62-69.

13. I. Villarreal, C. Jacobson, A. Leming, Y. Matus, S. Visco and L. De Jonghe, 
Electrochemical and Solid-State Letters, 2003, 6, A178-A179.

14. S. P. Jiang, J Electrochem Soc, 2015, 162, F1119-F1128.

15. M. Mori, T. Yamamoto, H. Itoh, H. Inaba and H. Tagawa, J Electrochem Soc, 1998, 145, 1374-1381.

16. M. Mori, Y. Hiei, N. M. Sammes and G. A. Tompsett, J Electrochem Soc, 2000, 147, $1295-1302$.

17. Q. L. Liu, K. A. Khor, S. H. Chan and X. J. Chen, J. Power Sources, 2006, 162, 1036-1042.

18. Z. Zhan and S. A. Barnett, Solid State Ionics, 2005, 176, 871-879.

19. B. Hua, M. Li, Y.-F. Sun, Y.-Q. Zhang, N. Yan, J. Chen, J. Li, T. Etsell, P. Sarkar and J.-L. Luo, Journal of Materials Chemistry A, 2016, 4, 4603-4609.

20. S. McIntosh, J. M. Vohs and R. J. Gorte, J. Electrochem. Soc., 2003, 150, A1305-A1312.

21. S. Cho, D. E. Fowler, E. C. Miller, J. S. Cronin, K. R. Poeppelmeier and S. A. Barnett, Energy \& Environmental Science, 2013, 6, 1850-1857.

22. K. F. Chen, L. Zhang, N. Ai, S. Zhang, Y. Song, Y. C. Song, Q. Yi, C. Z. Li and S. P. Jiang, Energy Fuels, 2016, 30, 1849-1857. 


\section{Figure captions:}

1. (a) The XRD pattern of as-prepared PBSCF calcined in air at $1050{ }^{\circ} \mathrm{C}$ for $10 \mathrm{~h}$ and (b) thermal expansion curve of PBSCF collected in air at temperatures ranging from 200 to $900{ }^{\circ} \mathrm{C}$.

2. (a) Polarization performance and (b) open circuit EIS of the cell with in situ assembled PBSCF cathode, measured at $750{ }^{\circ} \mathrm{C}$ before and after polarization at $500 \mathrm{~mA} \mathrm{~cm} \mathrm{~cm}^{-2}$ for $2 \mathrm{~h}$. The performance of a full cell prepared by conventional method with a GDC buffer layer is illustrated for comparison.

3. (a) Polarization performance and (b) open circuit EIS of the cell with in situ assembled PBSCF-GDC composite cathode, measured at temperatures ranging from 650 to $750{ }^{\circ} \mathrm{C}$ after polarization at $500 \mathrm{~mA} \mathrm{~cm}^{-2}$ and $750{ }^{\circ} \mathrm{C}$ for $2 \mathrm{~h}$. The initial performance at $750{ }^{\circ} \mathrm{C}$ before polarization treatment was also recorded for comparison.

4. (a) Performance stability of the cell with PBSCF-GDC composite cathode at $500 \mathrm{~mA} \mathrm{~cm}^{-2}$ and $750{ }^{\circ} \mathrm{C}$; and (b) open circuit impedance curves and (c) corresponding fitting data of the cell.

5. SEM micrographs of cross sections of (a) the full cell and (b) PBSCF-GDC composite cathode after the stability test.

6. AFM micrographs of (a) a blank YSZ electrolyte surface for comparison and (b-c) YSZ electrolyte surface in contact with in situ assembled PBSCF-GDC composite cathode after the cell stability test. (d) Height image of the area shown in (c). (e) The height profile along the line indicated in (d). 
7. (a) SEM images of the YSZ electrolyte surface in contact with in situ assembled PBSCF-GDC composite cathode after the cell stability test. (b) TOF-SIMS element representations from a $10 \times 10 \mu \mathrm{m}$ scan area indicated in (a) at the depth of $50 \mathrm{~nm}$.

8. Scheme of the in situ assembly process. 
Figure 1.
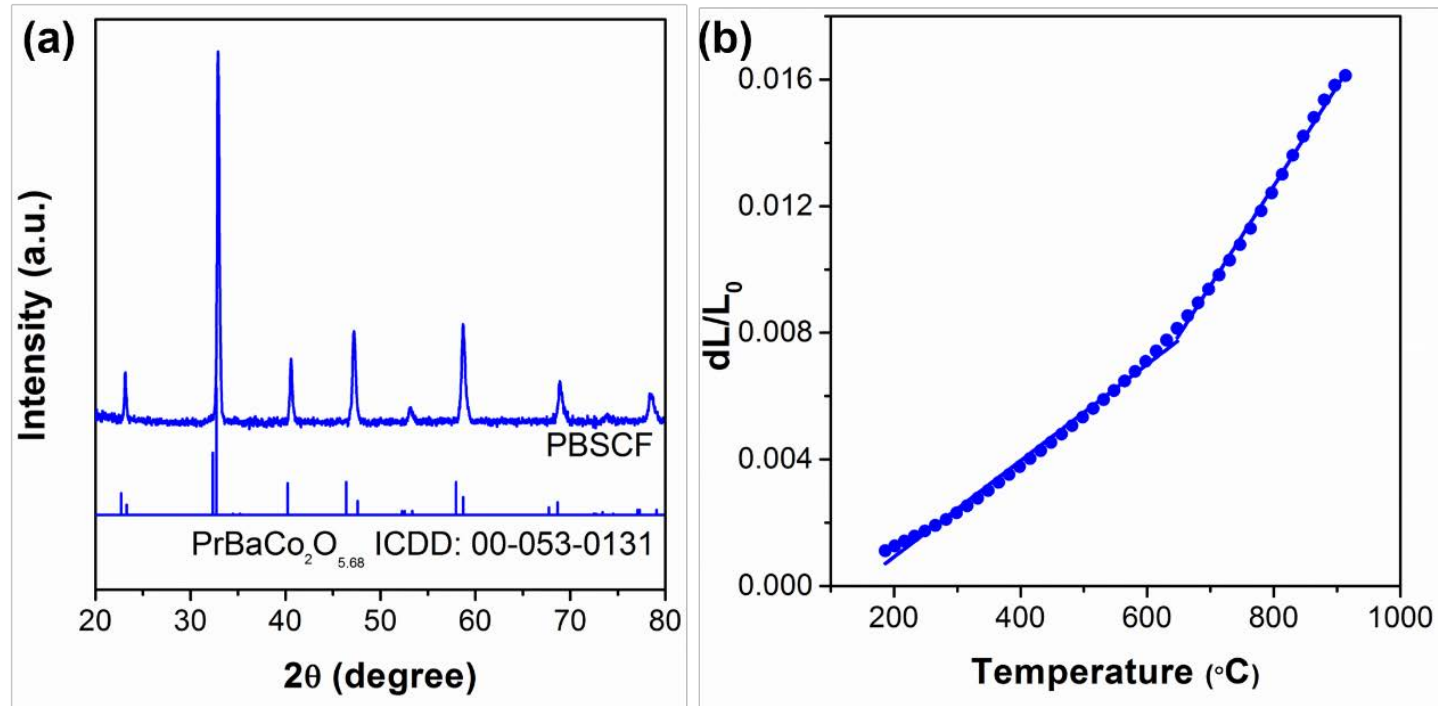
Figure 2.
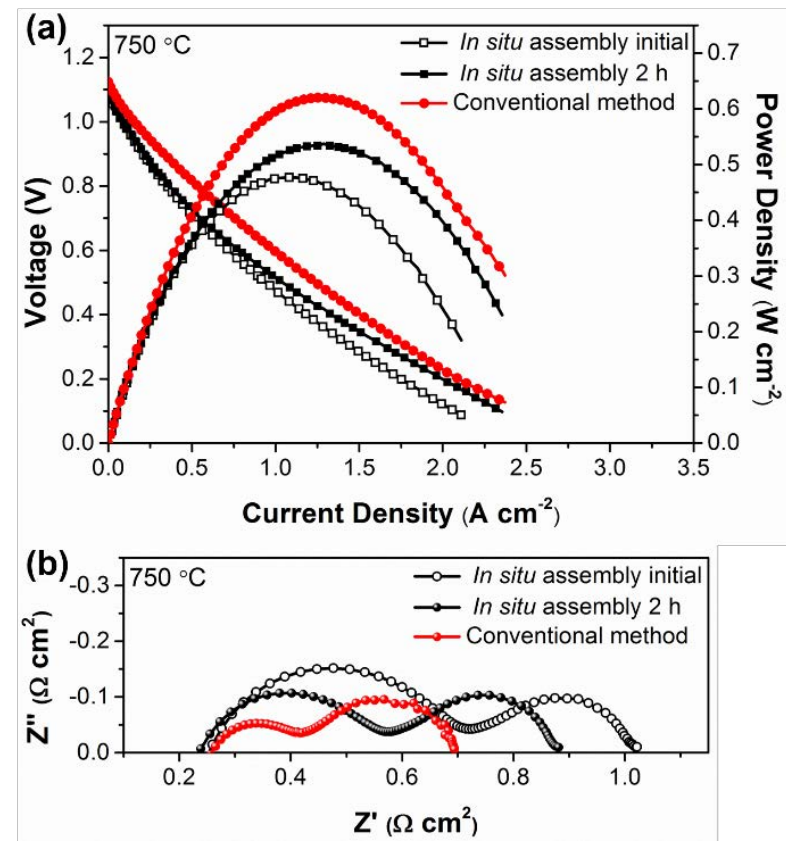
Figure 3.
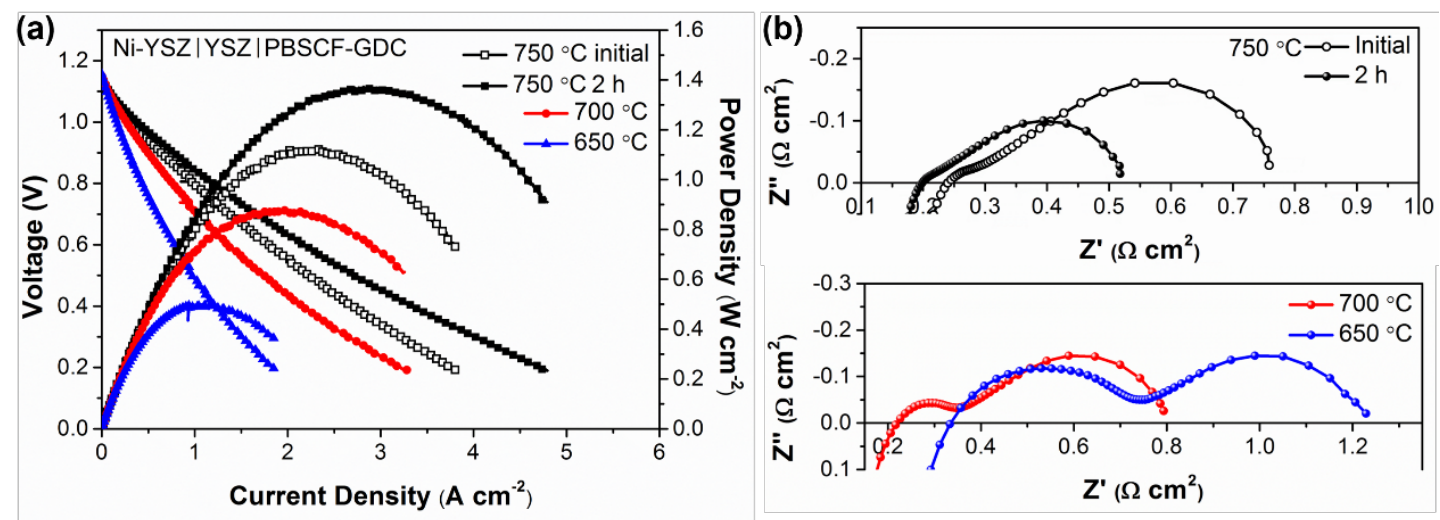
Figure 4.
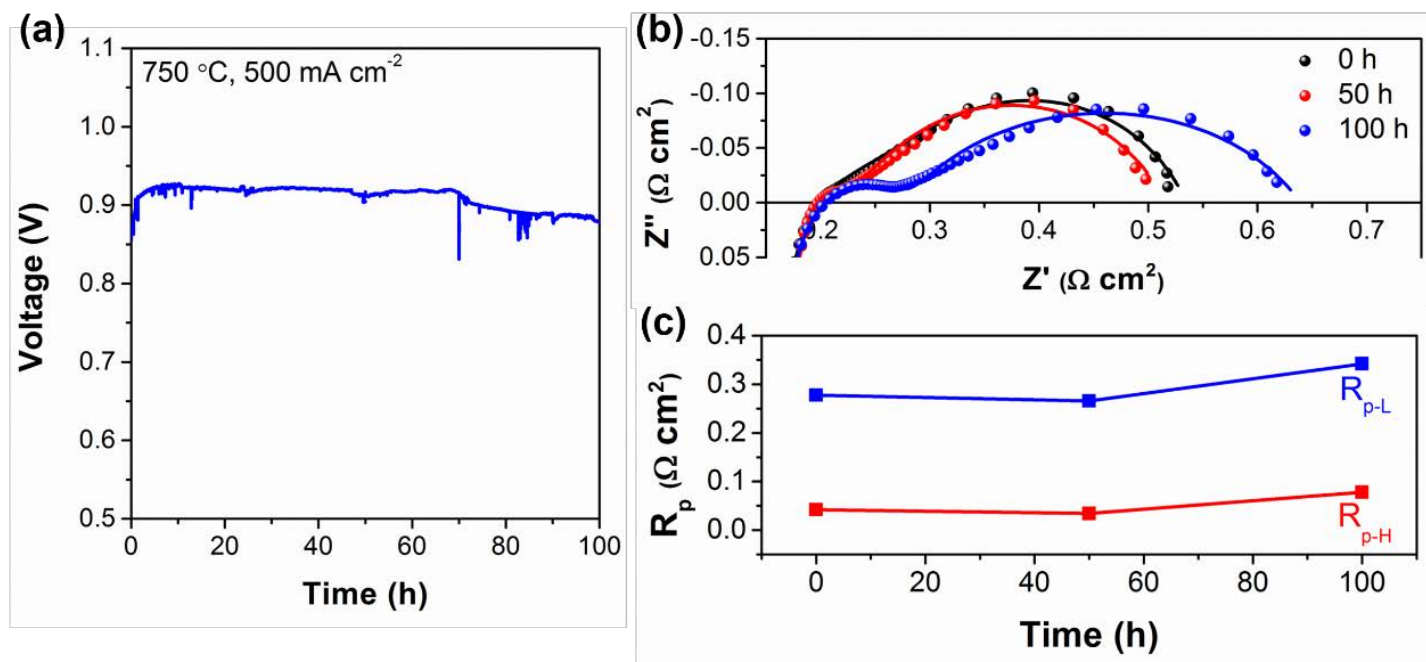
Figure 5.
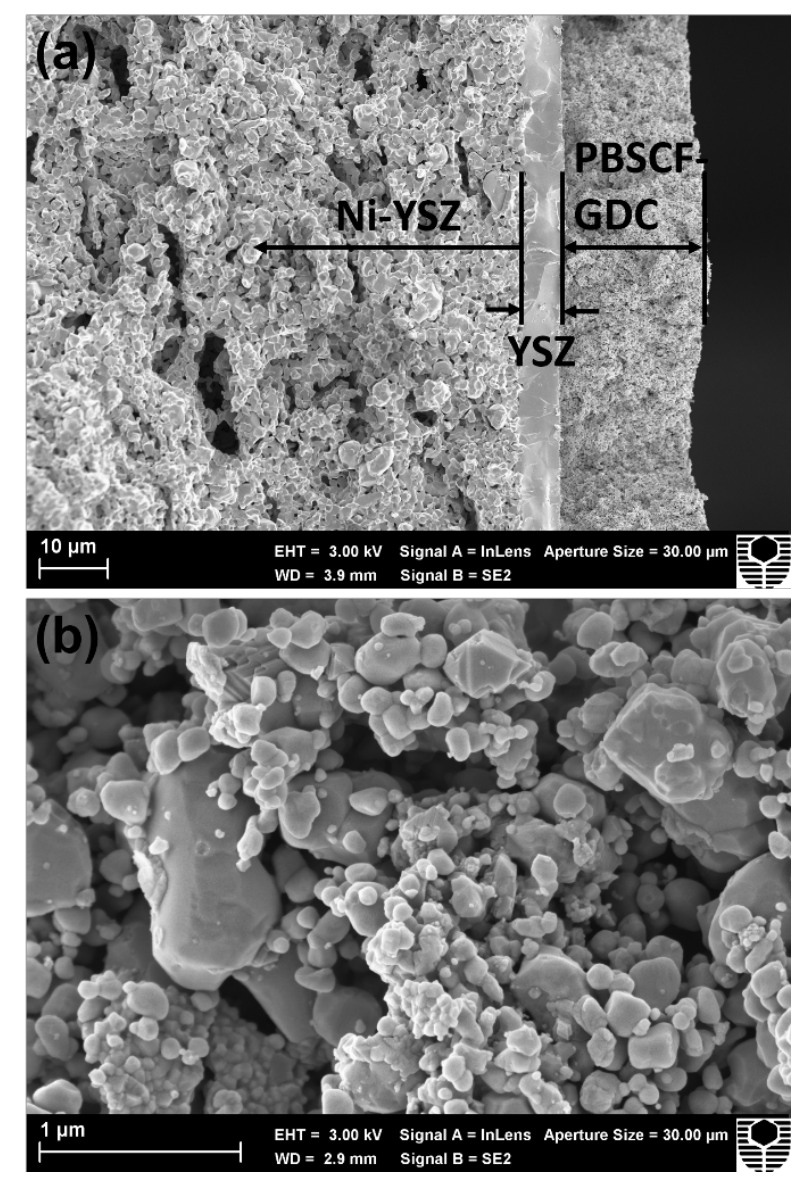
Figure 6.
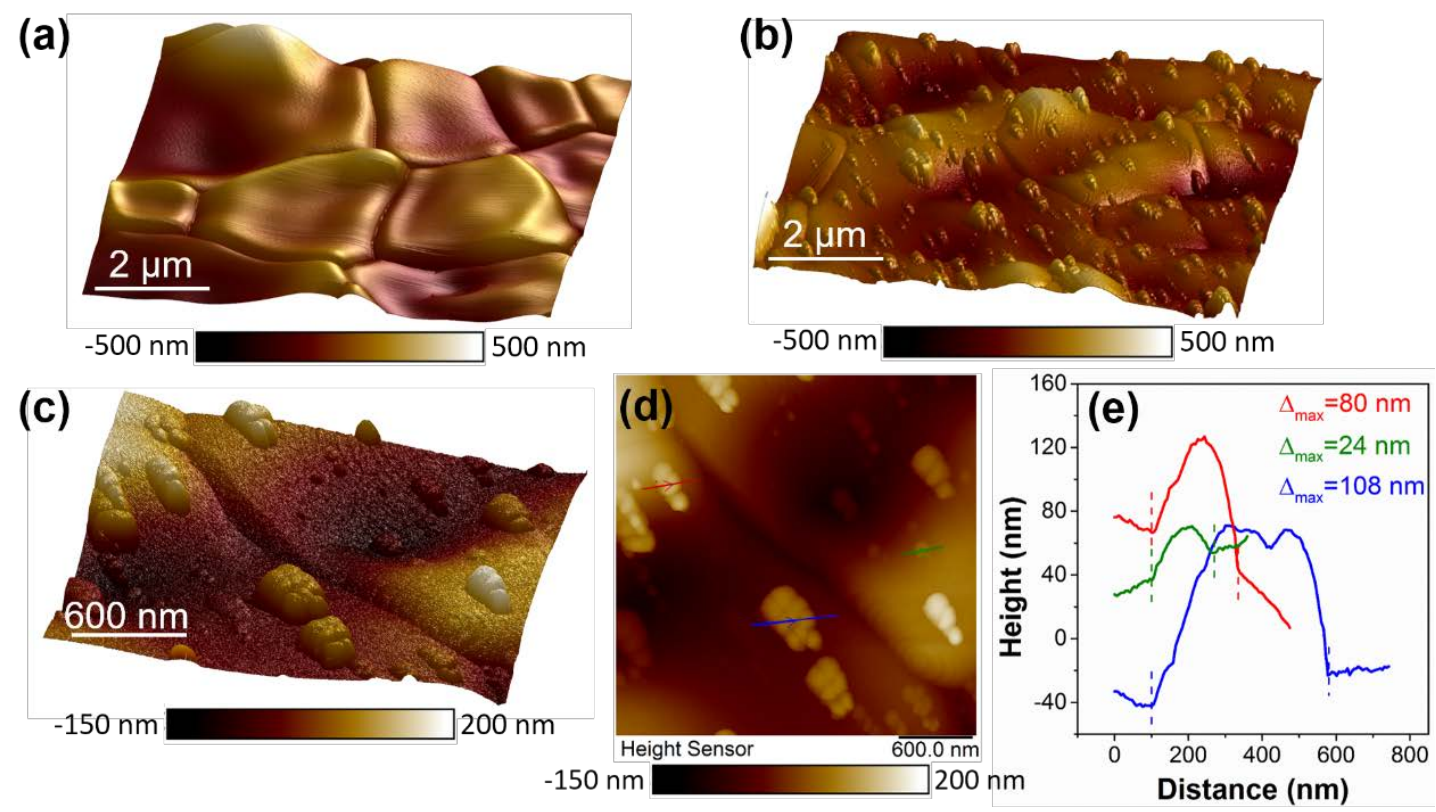
Figure 7.
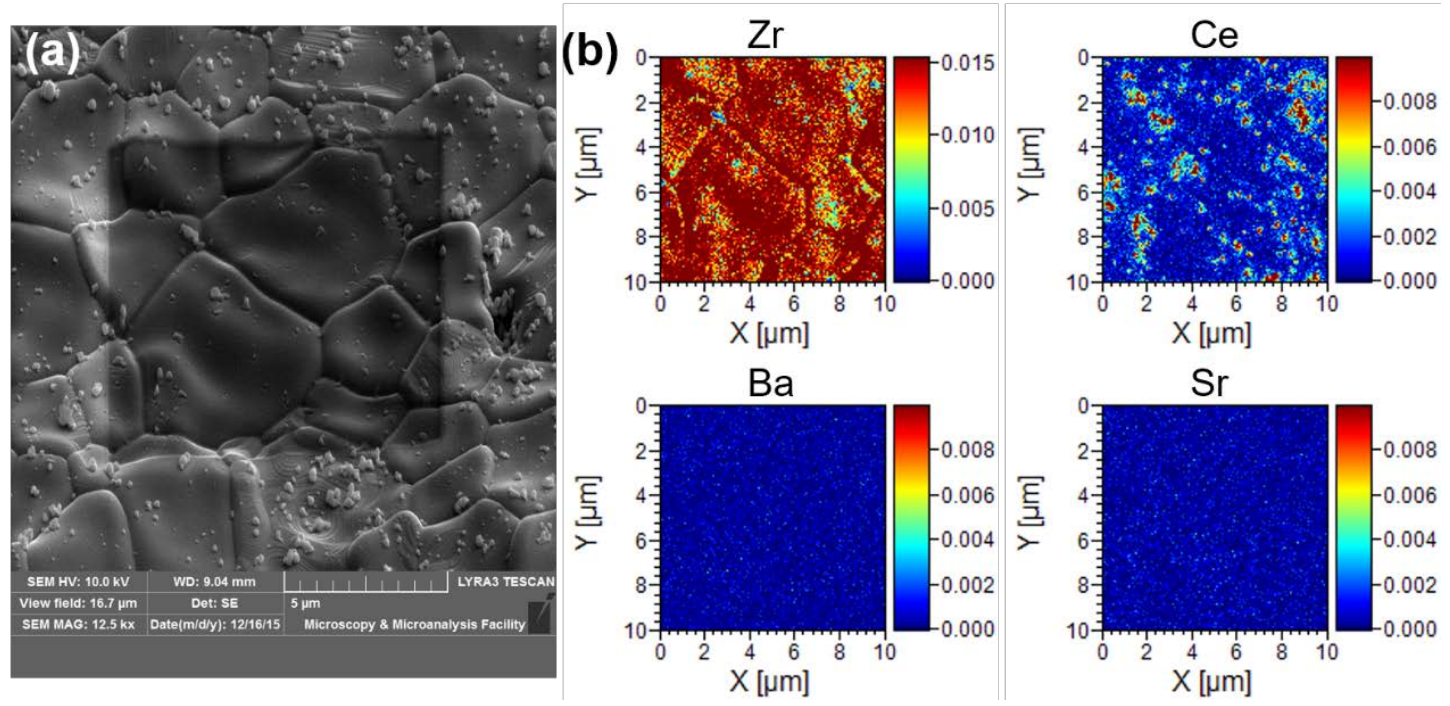
Figure 8.

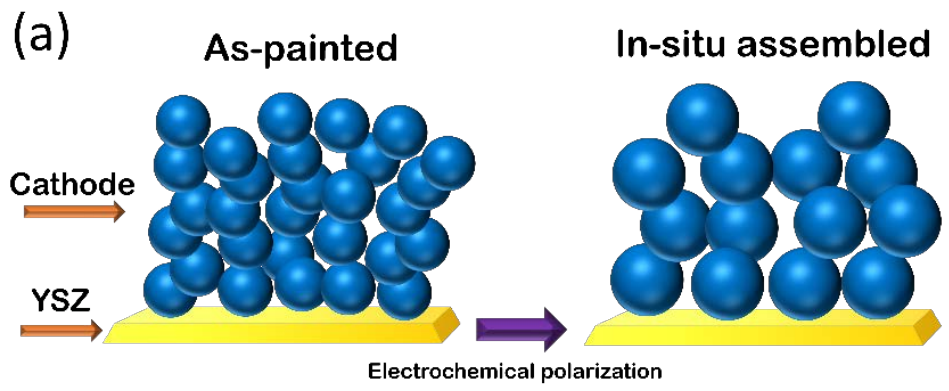

(b)

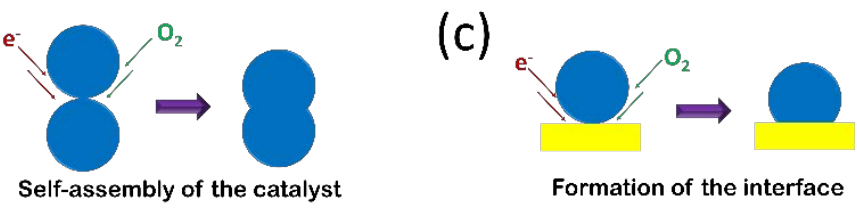

